\title{
RELATIONAL EQUALITY AND HEALTH ${ }^{1}$
}

\author{
BY KRISTIN VOIGT AND GRY WESTER
}

FinAL VERSION PUBLISHEd In Social PhILOSOPHY \& Policy 2015 31(2), 204-229.

\section{INTRODUCTION}

Health is important for a variety of reasons, perhaps most prominently because of its importance for individuals' well-being and ability to pursue different life plans. Not surprisingly, health has also become an increasingly interesting topic for political philosophers, who have sought to describe and address questions of justice arising in relation to health. This has included issues concerning the allocation of health-care resources $^{2}$ but also, more recently, attempts to take into consideration from the perspective of justice what we now know about the influence of social, economic, and political factors on health — the so-called "social determinants of health."3 Much of this literature works from a predominantly distributive understanding of justice, that is, an understanding of justice that is concerned with the distributive patterns of relevant outcomes, such as welfare, resources, or health. In the recent debate about egalitarianism, however, the distributive approach has come under criticism for missing "the point" of equality. So-called "relational" egalitarians have proposed a different way of conceptualizing equality, which focuses not on distributions as inherently important but instead on the quality of social relations among citizens and/or the ways in which social institutions "treat" citizens. While this approach is gaining traction among philosophers, and its possible implications for different policy spheres - such as higher education, the distribution of income, and the structure of the workplace - are considered, ${ }^{4}$ very little has so far been said about its implications for health.

In this essay, we explore a number of different ways in which the relational approach could have implications for health, with particular focus on health care, health inequalities, and health policy. Health raises interesting questions for relational egalitarians, particularly in light of emerging epidemiological evidence about the possible role of material factors and broader social circumstances in shaping health outcomes. Much of this essay is exploratory in that it seeks to explore different avenues that relational egalitarians could pursue to account for issues around health. However, our discussion also highlights some tensions and difficulties relational egalitarians might encounter, as well as some discontinuities between the implications of a relational account and current discourse on health equity. At the same time, the relational account also adds some interesting perspectives to the current debate, because it highlights concerns that are captured only to a limited extent by distributive theorists, especially in relation to health care and health policy.

We begin, in Section II, by outlining the central arguments and positions of the relational account and its understanding of equality. In Section III, we consider how the relationship between justice and health is currently understood in the literature. Sections 
IV through VII consider various ways in which questions concerning health and healthcare resources could be addressed within a relational framework. Here, we discuss possible implications of the relational approach for health care, inequalities in health, and health policy. As we suggest, while there are some important considerations about health that a relational perspective can add to current debates (particularly when it comes to health policy and the kinds of strategies we pursue to improve population health and/or reduce health inequalities), many of the more specific implications of the relational perspective for health remain unclear. Section VIII concludes.

\section{RELATIONAL EQUALITY}

The family of views we refer to as "relational" has, to a large extent, been developed in opposition to a growing literature that regards questions of equality as concerned with the fairness of distributions of one or more relevant goods in a certain population. On such accounts, the aim is to determine the conditions under which a distribution - of income, resources, well-being, or some other "currency" of justice can be considered fair or unfair. ${ }^{5}$ Relational theories, on the other hand, view equality as a social and political value and are primarily concerned with "egalitarian social relations."6 This approach has been developed in two different directions. On the first, the primary concern is that individuals (or citizens) should relate to one another as equals; different versions of this social objective have been referred to as "equality of status,"7 "social equality," respects, they all single out phenomena such as oppression and status hierarchies as problematic. The phrase "a society of equals"10 is often used to characterize the ideal of society these views envisage. The second family of relational approaches focuses on how institutions treat, and the attitudes they express toward, individuals. ${ }^{11}$ For such approaches, neglectful, disrespectful, or intentionally harmful treatment by institutions toward citizens is considered to be the primary target of egalitarian concern.

It is important to understand the precise disagreement between relational and distributive perspectives, not least because there is significant overlap in the kinds of scenarios each of these two accounts identifies as problematic. On the one hand, distributive egalitarians can acknowledge that the issues of central importance to the relational egalitarian - i.e., the quality of social relations - matter, but believe that they can be captured within a distributive framework. For example, relational "goods" could to some extent be accounted for within a distributive conception of equality by including "status" or "respect" as one of the things that ought to be distributed in a particular way. 12 Accounts that view distributive equality as the sole requirement of justice are also consistent with the view that justice requirements must be weighed against relational considerations (which would then be described as non-justice requirements). For example, in G. A. Cohen's account, the value of "community," which captures considerations similar to those that lie at the heart of relational accounts, seems to compete with the pursuit of justice (understood as distributive equality) in this manner. ${ }^{13}$

Relational egalitarians, on the other hand, often allow that their approach has distributive implications. In particular, at least some relational egalitarians argue that limits must be placed on permissible levels of income inequality. Thus, relational 
egalitarianism can have implications for the distributive outcomes that are considered acceptable or problematic. However, any such implications would not be understood as independent requirements of fairness (as distributive theorists such as Cohen might stipulate) but are instead to be derived from a broader understanding of equality as a social and political value. ${ }^{14}$

While there is therefore clearly some degree of overlap between distributive and relational frameworks in terms of the situations they identify as problematic from the perspective of equality and the remedies they are likely to favor, distributive and relational approaches come to such judgements through very different lines of reasoning. Thus, relational egalitarians can complain that even to the extent that distributive theorists object to relational inequalities, they do so for the wrong reasons: they object not to social inequality as such but to whatever distributive inequalities it produces. Distributive egalitarians, of course, can make a parallel argument: to the extent that relational egalitarians object to distributive inequalities, they do so because distributive inequalities undermine or are inconsistent with relational equality, not because distributive inequalities are in themselves unfair. Despite their likely agreement on a number of concerns, then, relational and distributive egalitarians rely on distinct conceptions of equality.

Our concern in this essay is with the implications relational egalitarianism might have for health. As we explained above, health has become of increasing interest to theorists of distributive equality, but so far relational egalitarians have said little about this topic. There are many open questions about the relationship between the ideal of social equality and health. In particular, much of the current literature on justice and health is concerned with inequalities in health outcomes between different socioeconomic groups; to what extent - and for what reasons - do relational egalitarians share this view? How do the questions they ask about various issues surrounding health, such as health care, health inequalities, and health policy, differ from the questions distributive theorists are concerned with? Does the relational perspective add anything to current debates about health and health inequalities that is not captured by distributive approaches? This essay seeks to begin to address these questions.

\section{JUSTICE AND HEALTH}

Health is a good that matters enormously to our flourishing and quality of life. Health is important because it is in our interest to remain free from pain and suffering, to have the functional capacity to engage in a wide range of ordinary human activities, and to live a life of a "normal" lifespan. ${ }^{15}$ Not surprisingly, health is one of the main determinants of subjective well-being. ${ }^{16}$

It has also been noted that health seems to have taken on a special kind of significance - a symbolic value, perhaps — in contemporary Western societies. ${ }^{17}$ This is often reflected in claims that health is "special" and that inequalities in health are morally more objectionable than inequalities in other goods. Thus, for example, Marchand, Wikler and Landesman claim that "Health, unlike income and other goods and services, seems special to many of us, in that the case for its equal distribution seems more compelling."18 
However, despite the importance of health for our life prospects and well-being, it is only recently that theories of justice have begun to address questions about health. Perhaps most prominently, Rawls's seminal work on justice is developed against the background assumption that citizens are in (more or less) full health, moving health deficits - and the question of how we ought to respond to them - beyond the purview of the theory. ${ }^{19}$ There are several reasons why one might bracket the question of health. One important reason concerns the scope of justice and the kind of good that health is considered to be. For some political philosophers, the scope of justice is limited to the distribution of "social" goods (such as income), whereas health has typically been considered a "natural good" or "fact of nature"; from such a perspective, health outcomes are beyond the scope of justice. The distribution of health care, on the other hand clearly a social good - would be an exception. Indeed, earlier initiatives to incorporate health into theories of justice have tended to focus on the allocation of health care. ${ }^{20}$

But as philosophers have become aware of epidemiological work on the influence of social factors on health, approaches to health in the context of justice have begun to change. Epidemiologists have been increasingly concerned with the so-called "social determinants of health," that is, factors relating to our living and working environments and broader social arrangements that shape health outcomes - and the level of health inequality - within a population. ${ }^{21}$ While uncertainties and disagreements about the causal mechanisms that underpin the associations between various social factors and health outcomes remain, ${ }^{22}$ the idea that it is a broad range of factors that shape population health has implications for many theories of justice in health. To the extent that these social factors are amenable to intervention, and to the extent that such interventions would have an impact on health outcomes, health can no longer be seen as a purely "natural" good. ${ }^{23}$ Insofar as one regards theories of justice to be concerned with the distribution of social goods, there is no prima facie reason to restrict oneself to the distribution of health care. Daniels, for example, has responded to the epidemiological research on the social determinants of health by revising his earlier account of justice in health to include not only health care but also "the full range of socially controllable factors that affect health and its distribution." 24

Much of the discussion on justice in health has focussed on inequalities in health. In this context, an inequality in health is typically defined as an inequality in life expectancy, healthy life expectancy, ${ }^{25}$ or differences in the prevalence of disease between groups. Sometimes these measures are used together. While health inequalities can be interpreted and measured in different ways, ${ }^{26}$ much of the literature focuses on social inequalities in health, that is, inequalities in health outcomes between socioeconomic classes. Both mortality and morbidity rates have been consistently demonstrated to vary systematically with social class, with lower life expectancy and higher incidence and prevalence of almost all major diseases in the lower social classes. While national averages of inequalities in life expectancies between the lowest and the highest socioeconomic groups typically range from three to seven years, ${ }^{27}$ inequalities of twenty years or more between the richest and the poorest have been documented in some cities, such as Glasgow in the United Kingdom and Baltimore in the United States. ${ }^{28}$ Inequalities in healthy life expectancies are larger, averaging ten years or more. ${ }^{29}$ But these inequalities do not merely represent inequalities between the rich and the poor; rather, they can be 
expressed as a gradient, with health improving steadily across the socioeconomic spectrum. These patterns have been documented in nearly every developed country, though the steepness of the health gradient and the magnitude of the inequalities have been found to vary across countries. ${ }^{30}$ Many (distributive) theorists consider these health inequalities as (at least prima facie) unfair and much of the debate proceeds from the sense that social inequalities in health are a problem of social justice.

Much of the philosophical literature on questions of justice and health considers health from a distributive perspective. Relational egalitarians, as we explained above, have criticized various aspects of the distributive perspective. How might their perspective on health differ from that of distributive theorists?

\section{A Society of Equals and the Provision of Health Care}

To the extent that health has featured in the relational egalitarian literature, the discussion has mostly focused on the provision of health care. Both Elizabeth Anderson and Samuel Scheffler include health care as one of several goods needed to meet people's basic needs. On both accounts, a society of equals requires adequate provision for basic human needs, because having one's basic needs met is a precondition for participation in society as an equal. Thus, for example, Anderson emphasizes the importance of protecting our basic functioning as human beings:

$[\mathrm{T}] \mathrm{o}$ be capable of functioning as an equal citizen involves not just the ability to effectively exercise specifically political rights, but also to participate in the various activities of civil society more broadly, including participation in the economy. And functioning in these ways presupposes functioning as a human being. ... To be capable of functioning as a human being requires effective access to the means of sustaining one's biological existence - food, shelter, clothing, medical care - and access to the basic conditions of human agency ... ${ }^{31}$

Basic health needs must be met in order for individuals to function as human beings and to stand as equals in society, and therefore relational equality guarantees access to health care to meet basic health needs.

However, as we have noted above, access to health care is only one of several factors that influence people's health outcomes. Much of the recent debate on health has developed precisely from the recognition that the contribution of health care to society's health is much more modest than previously believed, in comparison to the social determinants of health - the broader social and material environment in which we live. In particular, social inequalities in health persist even after the introduction of universal health care. ${ }^{32}$ While health care can often make a potentially dramatic difference as and when people fall ill, and while preventative services play an important role in detecting conditions early on, the "upstream" factors that cause illness and disease to occur in the first place seem to have a much greater impact on population health. This means that if there is a requirement to protect health, this may be met not only through the provision of health care but also through policies that address the socially controllable factors that influence health outcomes. Ought we perhaps to divert resources away from the health 
care budget toward policies that address the social determinants of health? Our knowledge about the social determinants of health seems to pose a challenge for a needbased justification for the provision of health care. ${ }^{33}$

How would relational egalitarians respond to this challenge? Would they endorse such a policy, if doing so could help ensure that more people achieve the minimum threshold of health required to participate as equals in society? If the goal is to meet basic needs so that citizens can be equal members of society, relational egalitarians should be open to the idea that health care may not be the only, or perhaps even the best, way of achieving this goal.

These issues prompt us to further question whether - from a relational perspective - the value of health care lies primarily in its instrumental function of promoting good health outcomes, or whether perhaps there are other dimensions to its value. The relieving of suffering could be one such further dimension; the sense of security that the availability of health care can give us and the knowledge that we will be looked after if we should fall sick, another. More important in the context of this discussion, however, is the notion that the provision of health care could have an expressive dimension. As Daniel Weinstock has suggested,

health care matters to us not because of what it does but because of what it means. Above and beyond the benefits that individuals accrue, health care has come to matter to people because it betokens the extent to which they are treated as deserving of equal care and respect. The social meaning of health care is tied in with our sense of ourselves as equal citizens in ways that other goods (say education) are not, even if for any objective construal, other goods matter just as much, perhaps even more, than health care per se. ${ }^{34}$

This suggested aspect of the value of health care fits well with the relational framework. Indeed, Anderson sometimes seems to suggest something along these lines. In her 1999 paper, she considers the implications of different perceptions of equality for the provision of health care by asking what proponents of different egalitarian views might say to an individual who had not purchased health insurance but now needed medical treatment. While, according to Anderson, a luck egalitarian would tell this person, "You are too stupid to run your own life," someone committed to the relational account Anderson favors would say the following:

"You have a moral worth that no one can disregard. We recognize this worth in your inalienable right to our aid in an emergency. You are free to refuse this aid once we offer it. But this freedom does not absolve you of the obligation to come to the aid of others when their health needs are urgent. Since this is an obligation we all owe to our fellow citizens, everyone shall be taxed for this good, which we shall provide to everyone. This is part of your rightful claim as an equal citizen."35

Having juxtaposed these two very different attitudes toward those who fail to purchase health insurance, she asks rhetorically, "Which rationale for providing health insurance better expresses respect for its recipients?"36 
That Anderson imagines egalitarians of different stripes providing reasons to the recipients of medical care and that she considers the difference in reasoning significant suggests that, for her, it is crucial not only that we provide aid but also that such aid is provided in a way that recognizes and expresses the equal status of citizens; the luck egalitarian approach seems problematic to Anderson because the rationale it offers for the provision of medical care is disrespectful. Further, the quote suggests that, for Anderson, providing medical care to those in need is based on recognition of the rights they have as equal citizens; a failure to provide care would express lack of concern and respect for the citizens concerned.

While this merely hints at the expressive role that health care might play for Anderson and is not sufficient to establish that this is in fact a part of Anderson's position, elsewhere she has endorsed the idea that laws and policies can, and often do, have an expressive character, i.e., expressing values and attitudes. The expressive dimension of a law, furthermore, as Anderson illustrates by referring to cases in U.S. legal history, can be independent of any particular effects that the law may have. ${ }^{37}$

A detailed account of the possible expressive dimension of health care has not been offered at this stage, but this line of reasoning would provide a further justification for the provision of health care that is independent of the health benefits that it provides. Developing this line of argument could help identify a uniquely relational response to questions about the provision of health care. In contrast, insofar as distributive egalitarians are concerned with distributive outcomes, and to a lesser extent with the means to achieve these, they are more likely to be concerned with the instrumental value of health care. ${ }^{38}$ Therefore, one would also expect them to be more likely to be swayed by the argument that if policies that address the social determinants of health will be more effective for either improving health outcomes or reducing health inequalities than the provision of health care, then we should shift resources away from the latter toward the former.

Relational egalitarians may, therefore, regard the health care system as important not only for its importance in meeting health needs but also because of the expressive importance of having such a system in place. Both of these considerations appear to play a role in Anderson's and Scheffler's arguments. However, as we explained above, to the extent that health care is important because of its role in achieving particular health outcomes, the question remains whether these arguments would not also extend to an obligation to address the social determinants of health. Further, the "expressive" argument in favor of health care leaves open many questions about what a "just" health care system might look like. For example, does the expressive importance of health care require equal access to all medical services provided by the health care system? Assuming that a publicly funded health care system could not afford to provide the very best of what our very advanced health care technology can offer in terms of treatment and care, and that health care services must be rationed, would relational egalitarians be opposed to the existence of private health care that allows individuals who can afford it to purchase better, more effective treatment and bypass waiting lists? ${ }^{39}$ Could inequalities in access to health care on the basis of ability to pay, or perhaps for other reasons, undermine equal social status? We will not pursue these questions further but simply note that there is much scope for further discussion here. 


\section{Thomas Pogge: A Hierarchy of Health Inequalities}

The discussion of the previous section focused on relational arguments surrounding the health care system. Does the relational account have any direct implications for health outcomes? How would relational egalitarians decide whether and why particular health deficits constitute injustices? Given that, unlike distributive theorists, relational egalitarians do not consider distributive outcomes to be a direct concern of equality, it is less straightforward to see how they would assess the justice or injustice of health inequalities.

To our knowledge, Thomas Pogge is the only relational egalitarian to engage directly with the question of when and why inequalities in health outcomes are unjust. Focusing on Pogge's way of distinguishing just from unjust health inequalities, this section raises broader questions about the possible implications of a relational approach to health inequalities. Note, however, that while Pogge's account can be described as relational, its focus is very different from that of approaches such as Anderson's and Scheffler's. Whereas Anderson and Scheffler are primarily concerned with the status of citizens and the relationships among them, Pogge focuses instead on how institutions "treat" citizens; his understanding of justice is "relational" in the sense that it involves "a relation between particular agents and recipients . . . : to be just is to give equitable treatment." 40 Much of the argument we describe in this section is based on this particular understanding of which relations matter from the perspective of equality, and it is not clear that these commitments would follow from the views that Anderson and Scheffler endorse.

The focus of Pogge's argument is on global health and the influence of poverty on the burden of disease. He criticizes what he calls "purely recipient-oriented views" that is, views of justice that on our terminology would be considered distributive - for failing to take into account the causes of particular health deficits. How the social order contributes to the development of the health deficit, Pogge argues, is crucial to assessing whether it constitutes an injustice and, if it is unjust, how great that injustice is.

Pogge introduces the "V example" to illustrate different ways in which social institutions can bring about a particular health deficit. The $\mathrm{V}$ example describes six different scenarios; in all of them, social arrangements lead some individuals to lack a certain nutrient, V. In scenario 1, this nutritional deficit is "officially mandated," resulting from a law that prevents some people from accessing the nutrient. In scenario 2 , it is legally authorized actions of individual citizens that lead to the deficit: those selling $\mathrm{V}$ may legally refuse to provide it to certain citizens. In scenario 3, "social institutions foreseeably and avoidably engender (but do not specifically require or authorize)" the deficit: poor economic arrangements leave some without the financial resources to purchase the nutrient. In scenario 4, the conduct of private individuals - which is legally prohibited but the prohibition is not enforced - leads to the deficit. In scenario 5, social institutions avoidably leave the effects of a natural health problem unmitigated: some individuals cannot metabolize the nutrient but "avoidably lack access" to the required treatment. Finally, in scenario 6, social institutions avoidably leave the effects of a "selfcaused" (not natural, as in scenario 5) defect in place: the inability to metabolize the nutrient is here due to the individuals' own prior choices. ${ }^{41}$ 
Pogge draws two conclusions from this example that are particularly important for our purposes. First, Pogge suggests, scenarios 1-6 are of decreasing moral weight. While he does not provide a detailed argument for this particular ordering and calls it an "intuitive, pre-reflective judgement," 42 the criteria that are to determine this ranking are, on the one hand, the nature of the causal role that institutions have played in the development of the health deficit and, on the other hand, the attitude that they express toward their citizens. These two factors are crucial in distinguishing unjust health deficits from those that are not unjust, and different kinds of causal role and/or institutional attitudes will lead to different "degrees" of injustice. Second, in accordance with the moral "weight" and different degrees of injustice each of these different scenarios represents is the urgency to address them: other things being equal, the more unjust a particular health deficit, the more urgent it is to address that deficit.

More broadly, such an account does not identify a range of permissible — or ideal - health distributions. A given health deficit or distribution of health cannot in itself be just or unjust because justice cannot be tied to outcomes alone; we also need to know how social institutions and arrangements are related to the health condition (or health distribution) in question. If equality is understood in terms of treating or relating to others in certain ways (with respect, as equals, recognizing their equal membership in a scheme of cooperation, and so on), then health conditions that result from institutions' failure to meet this requirement will be more unjust (and addressing them will have greater urgency) than health deficits that have no such connection to institutional failings.

One implication of this approach is that, other things equal, poor health outcomes with social causes are more unjust than those with natural causes because the latter do not result from unjust "treatment." Pogge thinks that natural health deficits could still be unjust if (as in scenario 5 of his $\mathrm{V}$ example) institutions could provide treatment but fail to do so; but other things being equal, they will be less unjust - and less urgent to address - than health deficits with social causes.

One interesting implication of his account that Pogge explicitly addresses is that a full assessment of the urgency to address particular health needs must be based not only on the level of injustice involved but also the severity of the health condition in question. In fact, he allows that the severity of the outcome can sometimes outweigh considerations about the injustice of the outcome. Referring to the scenarios in the V example, he notes:

Medical conditions become less weighty, morally, as we go through the list. But less weighty medical conditions may nevertheless outweigh weightier ones if the former are more severe or more numerous or more cheaply avoidable than the latter. In this way, an advantage in reducing Scenario 4 type deficits may outweigh a much smaller disadvantage in engendering Scenario 3 type deficits, for example. ${ }^{43}$

In the $\mathrm{V}$ example, the health deficit is equally severe across the different scenarios; our assessment of the moral urgency to address the health needs therefore varies only because of the different degrees of injustice involved. In the real world, of course, we will be faced with health deficits that have different levels of severity, and we may find ourselves faced with, on the one hand, health deficits that are very severe but involve little or perhaps even no injustice and, on the other hand, health deficits that 
involve significant injustices but are much less severe. On Pogge's account, then, the severity of a health deficit enters the "equation" as a consideration that must be weighed against the requirement to address injustices.

Pogge's account of how we are to assess the justice or injustice of particular health deficits has two implications that are particularly relevant for our purposes. First, it is not clear how easily this argument fits with other lines of argument that relational egalitarians such as Anderson and Scheffler may want to develop. In particular, note possible tensions between Pogge's argument and the considerations discussed in the previous section regarding relational egalitarians' views on health care. Whereas Anderson and Scheffler seem to be concerned that citizens must have access to medical care in order to protect their needs as human beings, and to ensure that their status as equals is recognized, Pogge's view implies that institutions - including, presumably, the health care system - should be designed so that they (other things being equal) give greater priority to unjust health deficits over those that are unfortunate but not unjust. He notes that "we should design any institutional order so that it prioritizes the mitigation of medical conditions whose incidence it substantially contributes to," 44 while scenarios 1-3 of the $\mathrm{V}$ example are instances in which social institutions can be said to "substantially contribute to" health deficits. On the one hand, as we mentioned above, not all relational egalitarians may be committed both to Pogge's conclusions and to the kind of relational egalitarianism Anderson and Scheffler propose; the difference in emphasis when it comes to the goals that the health care system should pursue may simply reflect the differences between these two kinds of approach. On the other hand, a different conclusion might be drawn by relational egalitarians who think that both of these accounts capture important aspects of the kinds of social relations egalitarians should be concerned with. They might want the health care system to pursue different - and possibly competing - goals: on the one hand, to prioritize the treatment of health care needs in relation to the level of injustice involved in bringing about the need and, on the other hand, to provide health care to ensure that individuals' basic needs as human beings are met. It is, of course, not necessarily an objection to the relational account that it might result in more than one objective that we would want the health care system to pursue. However, when relational egalitarians turn to the implications of their approach for health, which goals the health care system should pursue and how to address possible conflicts between different goals, are some of the questions that would need to be addressed.

A second implication of Pogge's argument is that it could identify a broader range of health inequalities as unjust than might appear to follow immediately from a relational account. In particular, his approach opens up two lines of argument that relational egalitarians could make about health inequalities. First, he allows that where our social and economic arrangements lead to health deficits, these can constitute injustices even if governments do not intend such effects. This could have far-reaching implications in the health context. In particular, if the argument is understood to include possible effects of the distribution of material goods on health outcomes, a government's failure to redistribute could arguably be seen as the kind of morally problematic institutional treatment that Pogge identifies in scenario 3 in the $\mathrm{V}$ example. This scenario exemplifies a case in which "social institutions foreseeably and avoidably engender . . . the nutritional deficit through the conduct they stimulate." 45 Here, social institutions are considered causally responsible for the nutritional deficiency because the deficiency is a 
consequence of some groups' severe poverty "within an ill-conceived economic order." 46 The implication is that if resources were more equally distributed, no person would be so poor as not to be able to afford essential nutrients. If, as many social epidemiologists argue, social arrangements - including, in particular, an unequal distribution of the social determinants of health - have significant effects on health outcomes, this could mean that the health deficits that result from a government's failure to seek a more equal distribution of these determinants would be unjust.

Depending on how the empirical facts work out, this could have far-reaching implications. Assume, for example, that we can improve the health of the lower socioeconomic classes by redistributing income from the higher socioeconomic classes. Assume further that there are diminishing marginal returns on improving health outcomes by improving absolute levels of income, such that reducing the income levels of the better-off (in order to redistribute to the worse-off) would not lead to a worsening of health in this group. ${ }^{47}$ In that case, redistributing income from the better-off to the worseoff would yield a pure health gain (to the worse-off), without making anybody else's health worse. Thus, insofar as social institutions can equalize the distribution of income and thereby improve health, it would follow that, when institutions fail to do so, they have "foreseeably and avoidably engendered" some proportion of health deficits in this population. More broadly, the more evidence we have about the influence of social arrangements - including, perhaps, income inequality but possibly also other factors the greater the scope for health deficits that are unjust because of institutional failure to prevent their occurrence through appropriate policies or institutional design. This line of argument - and its possible implications — seems to be anticipated by Christian Schemmel when he notes that

Unequal distributions of [socially produced] goods (and bads) constitute unequal treatment on the part of the basic structure, and have to be justified by justice-relevant reasons. . . . unequal impact of the basic structure on other goods that are often considered natural goods, for example, on personal health and genetic endowments . . requires such justification. ${ }^{48}$

The second kind of health inequalities that could become problematic if we adopt Pogge's argument is inequalities that have natural causes but that could be addressed by social institutions. In scenario 5 of the $\mathrm{V}$ example, the health shortfall is caused by "social institutions avoidably leaving unmitigated the effects of a natural defect: certain persons are unable to metabolize $\mathrm{V}$ due to a treatable genetic defect, but they avoidably lack access to the treatment that would correct their handicap." 49 Thus, health deficits with natural causes can be unjust if treatment is available but not provided by governments.

Importantly, however, Pogge's conclusion seems to rest on the judgment that the decision not to provide a particular treatment constitutes unjust treatment and/or expresses a problematic kind of attitude toward those in need. In the absence of such a judgment, his account would not identify the health deficit as unjust. Many instances in which governments fail to provide treatment, however, may not meet this requirement, for example when the treatment is very expensive and our resources would be better spent on other treatments. The precise implications of this aspect of Pogge's argument 
therefore depend on how we are to decide under what conditions failure to provide treatment constitutes wrongdoing.

The arguments Pogge presents open up the possibility that a broader range of health inequalities could be considered unjust from a relational perspective than one might initially assume. While relational egalitarians make reference to the injustice of distributive inequalities that are caused by unjust social relations, ${ }^{50}$ the arguments suggested by Pogge would identify as unjust, on the one hand, health inequalities resulting from particular social arrangements - even if these arrangements are not in themselves unjust - and health inequalities with "natural" causes that are not addressed through appropriate intervention. At the same time, as we emphasized before, Pogge works from an understanding of relational equality that focuses on how institutions relate to individuals: it is because institutions fail to prevent particular outcomes that they become unjust. It is not clear that this line of argument would appeal to relational egalitarians, such as Anderson and Scheffler, whose primary focus is on how citizens relate to one another.

\section{An INDIRECT APPROACH to HEALTH INEQUALITIES}

Whereas Pogge's account seeks to provide independent criteria that would allow us to directly distinguish just from unjust health inequalities, some theorists have advocated what they call an indirect approach to evaluating when health inequalities are unjust. ${ }^{51}$ An indirect approach does not specify principles of justice applicable to health outcomes as such: instead, whether a given distribution of health is just or unjust depends on the justice or injustice of the social arrangements and/or processes that have brought about this particular health distribution. Thus,

inequalities in health are wrong not simply because actual health outcomes deviate from some pattern of health outcomes that is considered ideal, but rather because, and insofar as, they are the expression and product of unjust economic, social, and political institutions. ${ }^{52}$

And conversely, when our economic, social, and political arrangements are just, then the resulting health distribution in that population - including any "residual" health inequalities - is thereby also, by implication, just.

A proponent of the relational understanding of equality could adopt such an indirect approach to account for when health inequalities are unjust. For example, if we want to know to what extent a relational egalitarian would condemn social inequalities in health, we would need to examine whether and to what extent such inequalities would remain even if our economic, social, and political institutions - and the resulting distribution of material factors that shape health outcomes - are consistent with relational requirements. In the following, we consider the implications of a relational theory of equality for some of the major determinants of health. However, as we suggest, this indirect approach to justice in health cannot give us any clear indications about the scope and nature of health inequalities that relational egalitarians would condemn. On the one hand, the evidence about the influence of material factors on health outcomes is arguably fairly robust; but the extent to which relational egalitarians object to inequalities 
in such factors remains unclear. On the other hand, while relational egalitarians have provided much more-detailed accounts of what constitutes violations of equality in social relations, the empirical evidence on the influence of such factors on health outcomes is much less straightforward.

As we indicated above, there is a growing body of research in support of the importance of material conditions for population health. Material conditions include factors such as nutrition, sanitation, housing, residential neighborhood (e.g., levels of pollution, traffic, crime), material insecurity (e.g., job insecurity, housing insecurity), and working conditions (e.g., exposure to chemical, physical, or ergonomic health risks). ${ }^{53}$ According to the social determinants of health thesis, these factors can explain a large proportion of the health inequalities between different socioeconomic groups, because many of these material determinants of health are generally strongly associated with one's level of income: the lower one's income, the lower one's material standard of living, and the more precarious one's life circumstances. Insofar as the relational egalitarian would object to inequalities in access to material resources or exposure to material health risks, they would also condemn the health inequalities that these factors give rise to.

Although the relational conception of equality primarily concerns the quality and nature of social relations, it also has some implications for the distribution of income and other material resources. Insofar as a relational account specifies such distributive outcomes, there will also be some implications for population health outcomes. However, relational egalitarians have not provided detailed accounts of what their approach would imply for the distribution of material resources. There seems to be agreement among relational egalitarians that equality requires that we secure for everyone a level of material goods, including housing, income, and so on, that is sufficient to meet basic human needs (we discussed this strand of Anderson's and Scheffler's arguments in Section IV above). But the extent to which relational egalitarians would advocate further distributive requirements, above and beyond meeting basic needs, is unclear. Relational egalitarians do not view inequalities in income and other material goods as in themselves problematic, though they may nevertheless object to certain inequalities because and to the extent that they have certain consequences or causes. ${ }^{54}$

One of the primary reasons relational egalitarians may object to income inequalities is that they could lead to the emergence of status hierarchies or the marginalization of less well-off social groups. Income inequalities therefore become problematic for relational egalitarians when they threaten to undermine equal social relations in these ways. But it remains unclear how demanding this instrumental requirement is. One reason for this is that the precise nature of these implications depends not only on theoretical arguments about the nature of the relationship between individuals' status as equals and income inequality, but also on empirical questions - to which we do not yet have clear answers - about the influence of income inequalities on individuals' perceptions of themselves and others as equals. Perhaps for this reason, Scheffler refrains from providing any specification of the level of income inequality that his account permits, and suggests that supporters may favor "a system that tolerates either more or less inequality of income and wealth than luck egalitarianism does." 55 
Furthermore, it may be possible to make even large income inequalities consistent with social equality; echoing Michael Walzer, Anderson gives her support to the strategy of "blocking exchanges" between different "spheres" of goods, to prevent income and wealth from being converted into power and social standing, thereby undermining social and political equality. She argues that

the degree of acceptable income inequality would depend in part on how easy it was to convert income into status inequality ... The stronger the barriers against commodifying social status, political influence, and the like, the more acceptable are significant income inequalities. ${ }^{56}$

Clearly, therefore, the instrumental reason for restricting income inequality does not give us a determinate answer to what level of income inequality we would expect to see in a society of equals.

Relational egalitarians may also object to inequalities in income and other material goods if they are the result of unjust social relations. Racial discrimination is a central case here: in her latest book, Anderson provides detailed discussion of the many ways in which discrimination brings about inequalities in resources and opportunities. ${ }^{57}$ Importantly for our purposes, discrimination is a major cause of racial inequalities in health. ${ }^{58}$ These inequalities in resources and opportunities, as well as the health inequalities they bring about, would be unjust according to the relational account.

However, would comparable levels of inequalities in material advantage be unjust if they were not the result of unjust social relations? The answer to this question seems to be "no": it is not the material inequality in itself that is the issue, but rather the unjust processes by which it has been brought about. The reasons that relational egalitarians provide for condemning particular distributions as unjust, do not tell us anything about what a just distribution would look like.

More recently, Schemmel has set out to show that a relational theory of equality can require much more stringent constraints on income inequality than relational egalitarians such as Anderson anticipate. He argues that recognition of citizens' equal membership and participation in a cooperative scheme grounds a "presumption of equality" in the distribution of social goods. A relational theory of equality can also give us an intrinsic reason to restrict income inequality. ${ }^{59}$ It is not clear, however, whether other relational egalitarians see the link between social equality and distributions in the same way and, if they do, how stringent the resulting requirements for distributive inequality would be.

Overall, therefore, it remains unclear what levels of inequality in income, or other material resources, would be permissible in a society of equals as it is envisaged by relational egalitarians. A society of equals, it seems, could be consistent with a range of different social arrangements and with very different distributive patterns. Accordingly, it is difficult to say much about the implications for population health: we cannot make good predictions about the health outcomes and the level of (residual) health inequality we would expect to find in a "society of equals."

Some of the social determinants of health that have been considered in the epidemiological literature concern certain aspects of social relations, and thus relate more 
directly to the ideal of social equality — these include factors such as status hierarchies, social exclusion, and the psychosocial work environment. Health inequalities that are the result of social structures and practices that are unjust, according to the relational account, would also, then, be unjust.

However, so far there is a shortage of empirical evidence demonstrating that these factors really do affect health, and the significance of their potential contribution to the social gradient in health remains at best uncertain. Some of these psychosocial factors are believed to affect health via a stress-mechanism: experiences of low social status or exclusion, for example, are hypothesized to cause stress, either directly or via negative emotions such as shame and low self-respect, and (chronic) stress has been linked to several adverse health effects such as, for example, weakening of the immune system. ${ }^{60}$ But while the stress-mechanism and its negative impact on health is fairly well documented, it is much more difficult to show that macro-level social phenomena produce biological effects such as stress at the individual level. ${ }^{61}$ The significance of these psychosocial factors for health outcomes therefore remains controversial. ${ }^{62}$

Overall, it appears that the contribution of such psychosocial determinants of health to the social inequalities in health may be rather limited, insofar as we can determine this on the basis of the current evidence. Thus, while phenomena such as certain forms of status hierarchies and social exclusion constitute more-straightforward violations of the ideal of social equality, it is far from clear whether a society in which these phenomena were addressed would have different levels of health (inequality) than a society that contained relational inequalities.

If relational egalitarians want to rely on the indirect approach to assess the justice or injustice of particular health inequalities, then, the implications of their theory remain unclear. While relational egalitarians would object to many of the psychosocial factors that epidemiologists are considering, it is difficult to say, at this stage, how much of an impact they really have on health outcomes. With respect to material factors, however, where the empirical evidence seems much stronger in demonstrating a link to health outcomes, it is not clear what distribution of material factors is required by relational equality: many relational egalitarians do not seem to object to distributive inequalities in principle and are willing to accept possibly significant inequalities (Schemmel being an exception here). If epidemiologists are right about the link between these factors and health inequalities, then a society of equals could be compatible with significant health inequalities. On an indirect approach, any health inequalities that exist once the requirements of relational equality have been met, would not be problematic; the aim of reducing health inequality could not constitute a further, independent reason to redistribute material resources and income.

\section{Health Policy from a Relational Perspective}

In relation to questions of health policy, specific intervention strategies and the policymaking process more broadly, the relational perspective highlights important, relevant considerations - considerations that often fall beyond the immediate scope of a purely distributive perspective. When assessing policies from a distributive perspective, what matters is how well the policy in question achieves a desired distributive outcome: how 
well it equalizes people's health, well-being or income, for example. From a relational perspective, such concerns will also matter to the extent that certain distributions are expressive of, or instrumentally important for, social equality. But from a relational perspective, a different set of questions and concerns will be primary. How, precisely, could relational considerations shape policy decisions? One way in which relational equality might be reflected in policy decisions is in the processes through which policies are designed and decided upon. Erika Blacksher, for example, envisages participation in decisions about public health policy as an important implication of relational considerations: in particular, such participation would increase the involvement of marginalized groups as "agents" of policy, rather than merely recipients. ${ }^{63}$ Calls for representation of different groups in policy decisions can clearly be motivated by relational values: efforts to include a variety of perspectives, including those of disadvantaged groups, reflect a commitment to treating all citizens with equal consideration and respect. This is not to say, of course, that such considerations couldn't also become relevant from a distributive perspective: to the extent that policies become more effective when we take into account how they will be perceived by particular groups - especially disadvantaged groups whose perspectives are often excluded from traditional policy-making processes - participation may well enhance the outcomes policies aim to achieve. For distributive approaches, however, participation remains important only for instrumental reasons.

In a much more direct way, relational considerations can also apply to the design and framing of policies: from a relational perspective, policies ought to reflect or promote equal concern for, and social equality among, citizens, and this consideration is independent of any expected distributive effects of the policy. Certain health policies (broadly conceived) can be seen as "expressing" relational (in)equality. For example, requirements that public buildings be made accessible for wheelchair users or the provision of health education information in Braille are based not only on concerns about outcomes (buildings and information being accessible to everyone) but also - and perhaps more importantly - expressive considerations: such policies express respect and consideration for groups that would be excluded if we were guided primarily by concern for majority groups.

The expressive dimension of public policies is, we think, an important aspect of policy-making, and one that relational approaches can help us think about more systematically. Policies, and the arguments through which they are supported, can express attitudes toward (groups of) citizens. Distributive perspectives are not well equipped to capture this type of concern, or at least they cannot capture it directly: distributive perspectives will focus on the effects of policies on outcomes; if no such effects can be found, or if there even are positive effects, this will affect the distributive egalitarian's judgment. To illustrate these concerns in relation to public health and health policy, let us consider two policies that have been proposed for their positive effects on health and health equality but might fall foul of relational requirements: paternalistic interventions and denormalization strategies.

Much of the philosophical presumption against paternalism rests on the concern that paternalist interventions place inappropriate limits on individuals' liberties. ${ }^{64}$ However, paternalistic interventions can also seem problematic for what can be described 
as relational reasons. To our knowledge, relational egalitarians have not explicitly addressed the issue of paternalism; Anderson cites paternalism as straightforwardly problematic, ${ }^{65}$ but she does not discuss it in detail. It is worth considering in more detail, therefore, the debate on paternalism, in which the notion that paternalism may communicate disrespect toward individuals subjected to interference has become a central issue.

A central feature of paternalism is that the person acting paternalistically believes that he or she is qualified to act on the other person's behalf. Because of this, as Douglas Husak explains, "paternalistic treatment, by definition, seems to imply a shortcoming or deficiency on the part of the subject of the interference" and "a lack of rationality, prudence, foresight, intelligence, maturity, or some other deficiency or shortcoming in which the alleged inferiority consists seems necessary before paternalistic treatment could be thought appropriate."66 Similarly, Seana Shiffrin emphasizes that paternalistic interventions stipulate an asymmetry of knowledge and competency between the agents involved. From this perspective, the expression of disrespect becomes a central feature of paternalistic interventions:

The essential motive behind a paternalistic act evinces a failure to respect either the capacity of the agent to judge, the capacity of the agent to act, or the propriety of the agent's exerting control over a sphere that is legitimately her domain.... Paternalistic behaviour is special because it represents a positive... effort by another to insert her will and have it exert control merely because of its (perhaps only alleged) superiority. As such, it directly expresses insufficient respect for the underlying valuable capacities, powers, and entitlements of the autonomous agent. Those who value equality and autonomy have special reason to resist paternalism toward competent adults. ${ }^{67}$

Husak, too, explicitly expresses this concern in terms of equality: "If a paternalistic relationship involves superiority and inferiority, the sense of equality that underlies such formulations of the autonomy principle is repudiated. On this view, there would be no place for paternalism in a world in which each agent regarded all others as moral equals." 68 The understanding of equality expressed here mirrors the concerns expressed by relational egalitarians.

In debates about public health policy, paternalist interventions are often seen as far less problematic than is the case in philosophical debates. What can the relational perspective add to our theorizing about paternalistic public health policies? A purely distributive perspective cannot capture (at least not fully) our sense that paternalistic interventions are problematic because of the disrespect they may convey to individuals affected by them. Perhaps most notably, Richard Arneson, whose work is informed by a distributive perspective, assesses paternalistic policies in terms of their effects on outcomes; from his perspective, paternalistic interventions are often conducive to (distributive) equality because they help us avoid bad outcomes for the worst-off. ${ }^{69}$ Relational egalitarians, on the other hand, can capture this concern about paternalistic interventions without having to frame it in terms of effects on distributions. 
Another strategy that highlights the importance of relational considerations is that of denormalization. Denormalization strategies aim to influence social norms surrounding behaviors that are to be discouraged, by making the behavior less visible and/or reducing its social acceptability. Denormalization has become a central aspect of public health strategies, especially in the context of tobacco control. ${ }^{70}$ One example that illustrates this approach is a recent UK TV spot that depicts a young woman in a bar with some friends. She exchanges glances with a man across the room until he approaches her. As he leans in to speak to her, his smile disappears and he looks disgusted. He gestures toward the drink in his hand to make his excuses and leaves. In the final shot of the clip, the woman, now by herself, is smoking a cigarette and looking puzzled about what has just happened. The caption, "If you smoke, you stink," appears, along with information identifying the campaign and link to a related website (entitled www.uglysmoking.info) that provides advice on cessation.

Adverts such as these are used in other policy areas as well. To give another example, a recent campaign to encourage breast-feeding depicted very pregnant women engaging in behaviors that are risky to the fetus and entirely gratuitous. In one spot, a pregnant woman is shown happily riding, and eventually being thrown off, a mechanical bull. This is followed by the tagline, "You wouldn't take risks before your baby is born. Why start after? Breastfeed exclusively for six months." 71

The use of denormalization strategies in public health campaigns has, of course, been criticized heavily. One important concern that critics have highlighted could also be described as a concern about relational equality: denormalization strategies risk stigmatizing certain groups - often groups who are already marginalized, disadvantaged or stigmatized in other ways. Again, relational egalitarians are in a better position to capture this concern than distributive theorists, who will object to the negative, unequalizing effects of stigma on outcomes, not the stigma itself.

What these two examples - paternalistic health policies and denormalization strategies - highlight is that relational egalitarians can capture a central aspect of what is problematic about these kinds of policies - something that cannot be fully, or appropriately, captured within a purely distributive perspective. The kinds of concerns that relational theories point toward are highly relevant to our evaluation of the policies under consideration. At the same time, of course, it is not clear how much weight these concerns should be given, relative to the possible health benefits that might result from such strategies. How such competing concerns are to be accounted for in a full assessment of these and other strategies is a crucial question we face in health policy.

\section{CONCLUSION}

Relational interpretations of equality, which focus on the relations between citizens and/or the ways in which institutions relate to and treat citizens, have been gaining traction in the philosophical literature. The relational interpretation of equality has emerged primarily as a critique of distributive accounts and provides a different understanding of what the "point" of equality is.

In this essay, we have considered what implications a relational conception of equality might have for health, focusing in particular on the distribution of health care 
resources, social inequalities in health, as well as health policy. While much remains to be done, we hope to have outlined some of the complexities involved in determining how and to what extent a relational theory of equality can be applied to questions about health. The implications of relational egalitarianism for health differ in various respects from the predominantly distributive approach taken in the literature. On the one hand, our discussion suggests that relational egalitarians can add important insights to the current debate, particularly in relation to the expressive dimensions of health care and health policy. On the other hand, it is difficult to pin down to what extent relational egalitarians will be opposed to health inequalities. In particular, it is unclear how relational egalitarians would respond to the ongoing empirical research about the social factors that shape health outcomes - this, we have suggested, could have significant implications for their account. Health presents a number of interesting challenges for relational egalitarians, and thus offers an opportunity to develop further the precise implications of their conception of equality.

1 Previous versions of this essay were presented to the Research Group on Constitutional Studies (RGCS) and to the Montreal Health Equity Research Consortium (MHERC), both at McGill University; at the Equality and Public Policy Conference, Ohio University; and at the Center for Interdisciplinary Studies at the University of Bielefeld. We are grateful to the audiences for their helpful comments and suggestions. For detailed written comments, we would like to thank J. Paul Kelleher and Govind Persad. This work was supported by the Canadian Institutes of Health Research (grant no. ROH-115214) and the Fonds de recherche du Québec - Société et culture (grant no. 172569).

2 Most prominently, Norman Daniels, Just Health Care (Cambridge: Cambridge University Press, 1985).

3 See, for example, Daniels, Just Health: Meeting Health Needs Fairly (Cambridge: Cambridge University Press, 2008) and Shlomi Segall, Health, Luck, and Justice (Princeton, NJ: Princeton University Press, 2009).

4 On education, see Elizabeth Anderson, "Fair Opportunity in Education: A Democratic Equality Perspective," Ethics 117, no. 4 (2007); on command structures in workplaces, see Anderson, "Expanding the Egalitarian Toolbox: Equality and Bureaucracy," Aristotelian Society Supplementary Volume 82, no. 1 (2008); on income 
distribution, see Christian Schemmel, "Why Relational Egalitarians Should Care About Distributions," Social Theory and Practice 37, no. 3 (2011).

5 Much of the relational critique is leveled against so-called luck egalitarian interpretations of distributive justice. According to luck egalitarianism, distributive inequalities are unfair unless they can be traced to choices for which individuals can be held responsible. While various aspects of luck egalitarianism have been criticized in the literature, the relational objection we are considering here applies not only to luck egalitarianism but to any theory that seeks to assess directly the fairness of distributions. The focus of the relational critique has been on the accounts offered in Ronald Dworkin, "What Is Equality? Part 2: Equality of Resources," Philosophy and Public Affairs 10, no. 4 (1981); G. A. Cohen, “On the Currency of Egalitarian Justice,” Ethics 99, no. 4 (1989) and Richard J. Arneson, "Equality and Equal Opportunity for Welfare," Philosophical Studies 56, no. 1 (1989).

6 Christian Schemmel, "Distributive and Relational Equality," Politics, Philosophy and Economics 11, no. 2 (2012).

7 David Miller, “Equality and Justice,” Ratio 10, no. 3 (1997).

$8 \quad$ Samuel Scheffler, "What Is Egalitarianism?” Philosophy and Public Affairs 31, no. 1 (2003).

$9 \quad$ Elizabeth Anderson, "What Is the Point of Equality?" Ethics 109, no. 2 (1999); "How Should Egalitarians Cope with Market Risks?" Theoretical Inquiries in Law 9, no. 1 (2008).

10 Scheffler, "What Is Egalitarianism?"

11 Thomas Pogge, "Relational Conceptions of Justice: Responsibilities for Health Outcomes," in Public Health, Ethics and Equity, ed. Sudhir Anand, Fabienne Peter, and Amartya Sen (Oxford: Oxford University Press, 2011); Schemmel, "Why Relational Egalitarians Should Care About Distributions"; "Distributive and Relational Equality." 
12 Jonathan Wolff and Avner De-Shalit, Disadvantage (Oxford: Oxford University Press, 2007); Kasper Lippert-Rasmussen, "Democratic Egalitarianism versus Luck Egalitarianism: What Is at Stake?” Philosophical Topics 40, no. 1 (2012).

13 G. A. Cohen, Rescuing Justice and Equality (Cambridge, MA: Harvard University Press, 2008); Why Not Socialism? (Princeton, NJ: Princeton University Press, 2009).

14 Scheffler, "What Is Egalitarianism?"

15 The definition of health is itself a difficult and complex matter, and it is beyond the scope of this paper to discuss the many issues this question raises. We will simply adopt Christopher Boorse's definition of health as the absence of disease. Disease, in turn is defined as a deviation from "normal species functioning," where the relevant species functionings are those parts and processes of the organism that contribute to survival and reproduction. See Christopher Boorse, "Health as a Theoretical Concept," Philosophy of Science 44, no. 4 (1977).

16 Paul Dolan et al., "How Does NICE Value Health?” British Medical Journal 339 (2009).

17 Daniel Weinstock, "How Should Political Philosophers Think of Health?" Journal of Medicine and Philosophy 36, no. 4 (2011).

18 Sarah Marchand, Daniel Wikler, and Bruce Landesman, "Class, Health, and Justice," Millbank Quarterly 76, no. 3 (1998): 454. For further discussion of the claim that health is "special," see Shlomi Segall, "Is Health Care (Still) Special?" Journal of Political Philosophy 15, no. 3 (2007).

19 John Rawls, A Theory of Justice, rev. ed. (Oxford: Oxford University Press, 1999).

20 Daniels, Just Health Care. See also Ronald Dworkin, "Justice in the Distribution of Health Care," McGill Law Journal 38, no. 4 (1993). In "What Is Equality? Part 1" and "What Is Equality? Part 2," he also considers the question of the problem of handicaps or how to respond to irremediable health deficits. 
21 For an overview of the current literature, see, for example, Paula Braveman, Susan Egerter, and David R Williams, “The Social Determinants of Health: Coming of Age," Annual Review of Public Health 32 (2011).

22 For discussion and different interpretations of the empirical evidence and what it tells us, see for example, Angus Deaton, "What Does the Empirical Evidence Tell Us About the Injustice of Health Inequalities?" in Inequalities in Health: Concepts, Measures, and Ethics, ed. Nir Eyal, et al. (Oxford: Oxford University Press, 2013), Michael Marmot, "Fair Society Healthy Lives," in Inequalities in Health: Concepts, Measures, and Ethics, ed. Nir Eyal, et al. )

23 Whether the current evidence base is sufficient to allow the conclusion that interventions addressing different aspects of the social determinants of health do, in fact, have an impact on health and health inequality is another question that epidemiologists disagree on. For relevant discussion, see Jay S. Kaufman and Sam Harper, "Health Equity: Utopian and Scientific," Preventive medicine 57, no. 6 (2013), Ted Schrecker, "Can Health Equity Survive Epidemiology? Standards of Proof and Social Determinants of Health," Preventive medicine 57, no. 6 (2013).

24 Daniels, Just Health, p. 13.

25 The average number of years a person expect to live in "full health" — in other words, life expectancy, as adjusted by subtracting years lived in less than full health due to disease, disability, or injury.

26 Defining the concept of health inequality is itself an inherently normative task, which raises a host of philosophical questions. We cannot address these questions in this paper. For discussion, see Sam Harper et al., "Implicit Value Judgments in the Measurement of Health Inequalities,” Milbank Quarterly 88, no. 1 (2010), Daniel Hausman, "What's Wrong with Health Inequalities?” Journal of Political Philosophy 15, no. 1 (2007), and Kasper Lippert-Rasmussen, "When Group Measures of Health Should Matter," in Inequalities in Health: Concepts, Measures, and Ethics, ed. Nir Eyal, et al. ) 
$27 \quad$ Martijntje Bakker and Johan Mackenbach, Reducing Inequalities in

Health: A European Perspective (London: Routledge, 2004).

28 Michael Marmot, The Status Syndrome: How Social Standing Affects Our Health and Longevity (New York: Times Books, 2004).

29 Bakker and Mackenbach, Reducing Inequalities in Health.

$30 \quad$ Johan P Mackenbach et al., "Socioeconomic Inequalities in Health in 22 European Countries," New England Journal of Medicine 358, no. 23 (2008).

31 Anderson, "What Is the Point of Equality?" 317, our emphasis. Scheffler argues along similar lines in "What Is Egalitarianism?" 23.

$32 \quad$ Iris Plug et al., "Socioeconomic Inequalities in Mortality from Conditions Amenable to Medical Interventions: Do They Reflect Inequalities in Access or Quality of Health Care?" BMC Public Health 12, no. 1 (2012), Douglas Black et al., Inequalities in Health: Report of a Research Working Group (London: Department of Health and Social Security, 1980).

33 Gopal Sreenivasan, "Health Care and Equality of Opportunity," Hastings Center Report 37, no. 2 (2007). See also Jonathan Wolff, Ethics and Public Policy: A Philosophical Inquiry (London: Routledge, 2011), chap. 6.

$34 \quad$ Weinstock, “How Should Political Philosophers Think of Health?” 429.

35 Anderson, "What Is the Point of Equality?" pp. 330-31.

36 "What Is the Point of Equality?" p. 331, emphasis added.

37 Elizabeth S. Anderson and Richard H Pildes, "Expressive Theories of

Law: A General Restatement," University of Pennsylvania Law Review 148, no. 5 (2000).

38 See, for example, Daniels, Just Health Care.

39 For discussion of such problems as they have recently arisen in the New Zealand context, see Elizabeth Fenton, "Mind the Gap: Ethical Issues of Private 
Treatment in the Public Health System," Journal of the New Zealand Medical Association 124, no. 1334 (2011).

$40 \quad$ Pogge, "Relational Conceptions of Justice," 146.
$41 \quad$ "Relational Conceptions of Justice," $156-57$.
$42 \quad$ "Relational Conceptions of Justice," 156.
$43 \quad$ "Relational Conceptions of Justice," 156, fn. 48.
$44 \quad$ "Relational Conceptions of Justice," 135.
$45 \quad$ "Relational Conceptions of Justice," 156, emphasis in original.
$46 \quad$ Ibid.
$47 \quad$ On the question as to whether this assumption might hold in the real world, see Angus Deaton, "Health, Inequality, and Economic Development," Journal of Economic Literature 41, no. 1 (2003).

48 Schemmel, "Why Relational Egalitarians Should Care About Distributions," 371-72, our emphasis.

49 Pogge, "Relational Conceptions of Justice,"156, emphasis in original.

50 See, for example, Elizabeth Anderson, The Imperative of Integration (Princeton, NJ: Princeton University Press, 2010).

$51 \quad$ For example, Norman Daniels, Bruce Kennedy, and Ichiro Kawachi, "Justice Is Good for Our Health," in Is Inequality Bad for Our Health? ed. Joshua Cohen and Joel Rogers (Boston: Beacon Press, 2000), Fabienne Peter, "Health Equity and Social Justice," in Public Health, Ethics, and Equity, ed. Sudhir Anand, Fabienne Peter, and Amartya Sen (Oxford: Oxford University Press, 2004). But see Gopal Sreenivasan, "Ethics and Epidemiology: Residual Health Inequalities," Public Health Ethics 2, no. 3 (2009) and Sudhir Anand and Fabienne Peter, "Equal Opportunity," in Is Inequality Bad for Our Health?" ed. Joshua Cohen and Joel Rogers (Boston: Beacon Press, 2000) for further discussion of this distinction. 
52 Peter, "Health Equity and Social Justice," 95.

53 For an overview, see Braveman, Egerter, and Williams, "The Social Determinants of Health."

54 For example, Anderson, "What Is the Point of Equality?" 326; Miller, "Equality and Justice."

$55 \quad$ Scheffler, "What Is Egalitarianism?" 24.

56 Anderson, "What Is the Point of Equality?" 326.

$57 \quad$ Anderson, The Imperative of Integration.

58 Racism is believed to affect health primarily through socioeconomic factors and material pathways, such as low income, lower quality housing and residential neighborhood, higher exposure to environmental health risks, and so on. See Braveman, Egerter, and Williams, "The Social Determinants of Health." Some of the negative health effects of being subjected to discrimination have also been attributed to increased stress; see Elizabeth A Pascoe and Laura Smart Richman, "Perceived Discrimination and Health: A Meta-Analytic Review," Psychological Bulletin 135, no. 4 (2009).

$59 \quad$ Schemmel, "Why Relational Egalitarians Should Care About Distributions," 370.

60 Braveman, Egerter, and Williams, "The Social Determinants of Health.”

61 David M Cutler, Adriana Lleras-Muney, and Tom Vogl, "Socioeconomic Status and Health: Dimensions and Mechanisms," in Oxford Handbook of Health Economics, ed. Sherry Glied and Peter Smith (Oxford: Oxford University Press, 2008).

62 John W Lynch et al., "Income Inequality and Mortality: Importance to Health of Individual Income, Psychosocial Environment, or Material Conditions,” British Medical Journal 320, no. 7243 (2000), Deaton, "What Does the Empirical Evidence Tell Us About the Injustice of Health Inequalities?”

63 Erika Blacksher, "Redistribution and Recognition," Cambridge Quarterly of Healthcare Ethics 21, no. 3 (2012): 326. 
64 This section draws on Kristin Voigt, "Paternalism and equality," unpublished manuscript.

65 Anderson, "What Is the Point of Equality?"

66 Douglas Husak, "Paternalism and Autonomy," Philosophy and Public Affairs 10, no. 1 (1981), 40-41.

67 Seana Valentine Shiffrin, "Paternalism, Unconscionability Doctrine, and Accommodation,” Philosophy and Public Affairs 29, no. 3 (2000), 220.

$68 \quad$ Husak, "Paternalism and Autonomy." 41.

69 Richard J. Arneson, "Paternalism, Utility, and Fairness," Revue

Internationale de Philosophie 43, no. 170 (1989); "Joel Feinberg and the Justification of Hard Paternalism," Legal Theory 11, no. 3 (2005).

70 Kristin Voigt, "'If You Smoke, You Stink.' Denormalisation Strategies for the Improvement of Health-Related Behaviours: The Case of Tobacco," in Ethics in Public Health and Health Policy: Concepts, Methods, Case Studies, ed. Daniel Strech, Irene Hirschberg, and Georg Marckmann (Amsterdam: Springer, 2013).

$71 \quad$ Also see Rebecca Kukla, "Ethics and Ideology in Breastfeeding Advocacy Campaigns," Hypatia 21, no. 1 (2006), for information on and discussion of this and similar breast-feeding campaigns. 